\title{
The Machine Prediction of the Mutual Trade between the PRC and the Czech Republic in the Global Extraordinary Situation
}

\author{
Jakub Horak $^{1, *}$, Jiri Kucera ${ }^{2}$ \\ ${ }^{1}$ University of Zilina, Faculty of Operation and Economics of Transport and Communications, \\ Department of Economics, Univerzitna 1, 01026 Zilina, Slovakia \\ ${ }^{2}$ Institute of Technology and Business in Ceske Budejovice, School of Expertness and Valuation, \\ Okruzni 517/10, 37001 Ceske Budejovice, Czech Republic
}

\begin{abstract}
.
Research background: International trade is a substantial constituent of the global and regional economic development. The analysis of mutual trade serves as a tool for a monetary expression of economic transactions between a particular country and its foreign partners for a specific period. For the Czech Republic (CR), the People's Republic of China (PRC) is the biggest exporter and the second biggest importer. The USA, however, imposes a number of economic sanctions against the PRC that do not have any significant impact on the trade between both countries and the overall growth of the Chinese economy, yet they affect the behavior of consumers and producers both in the USA and in the PRC.

Purpose of the article: The aim of this paper is to use machine learning for predicting the future values of the mutual trade between the CR and the PRC for one calendar year (i.e. 12 months).

Methods: Monthly data of these two states' import and export are used to predict bilateral trade flow. The time series begins in January 2005 and ends in April 2020. Thus, the time series contains 184 data lines. Artificial intelligence - artificial neural networks - is used to predict bilateral trade flow between the PRC and the CR. The development of trade is then compared with the mutual sanctions of the PRC and the USA.

Findings \& Value added: This is expected that the mutual trade balance to be negative from the perspective of the CR. COVID-19 or the sanctions imposed in the international trade will not significantly affect the development of the mutual trade between the CR and the PRC.
\end{abstract}

Keywords: international trade; sanctions; machine learning prediction; time series

JEL Classification: $C 45 ; F 17 ; F 51$

*Corresponding author: horak@mail.vstecb.cz 


\section{Introduction}

According to Drábek et al. [1], international trade has always been considered very important and has been paid great attention to. Balance of payment is used as a tool to provide one of the best analyses of external economic relations of a specific country and serves as a monetary expression of economic transactions between a specific country and its foreign partners in a given period. Li et al. [2] claim that international trade is a substantial constituent of regional economic development. Regions with faster international trade development prove to be regions with the highest level of economic development. Fürst and Pleschová [3] state that many renowned economists believe that successful international trade extends the consumer opportunities of a given country. According to Hnát and Tlapaf [4], the reasons why a country decides to open for international trade differ depending on the natural resources and conditions of a given country as well as on the specificity of consumer taste.

Since 2007, that is, since the global financial crisis, China's foreign trade has been growing faster than international trade. However, its driving forces now differ from those that prevailed in the past. According to Lemoine and Unal [5], the participation of the Chinese economy on global production chains by means of processing activities is no longer a key driving force of its trading performance. A new driving force of change is ordinary trade based mainly on the domestic demand and local inputs. China, which played the main role in the globalization process as an export base for multinational enterprises, is currently shifting to a common foreign trade system that is more integrated into the domestic economy.

What is interesting is the monitoring of the trade between the Czech Republic and the People's Republic of China. According to Gourdon et al. [6], both the People's Republic of China and the Czech Republic are countries with an open economy. Stehel and Šuleř [7] state that the People's Republic of China represents the biggest exporter and the second biggest importer for the Czech Republic. The Czech Republic has a huge trade deficit with China. The volume of Chinese imports in the CR is much larger and its structure is focused on capital goods and goods used for further production. According to Higgins et al. [8], the prevailing tradable groups are industrial products, market products, machines, and transport equipment. Liu et al. [9] state that both Chinese and Czech economy is focused on export rather than import. In terms of China, the share of foreign trade with the CR on the overall GDP is much lower than the overall share of the CR foreign trade with China on the total GDP. Compared to the CR, China is the U.S. less dependent on the export in the CR.

The current situation, which is defined by the PRC export to the CR, follows the global trend, as China's export has been reduced in the last two years. According to the estimates, no dramatic change of the trend was expected for the year 2018. The change of the trend in the Chinese export to the CR is contrasted with the permanent increase in the export of products and services from the CR to China. The upward trend remains despite the slow growth of the volume of the Czech export. This is evidenced by the fact that a wide range of Czech enterprises has found a long term market in China and that their position is strengthening [10]. For the first months of the year 2019, the CR trade deficit with China widened to CZK 90.9 billion (from CZK 75.8 billion in 2018). While this year, Czech export has fallen by about $4 \%$ year-on-year, import has risen by $17 \%$ [11].

Currently, states tend to use economic sanctions more often; however, they hardly ever achieve their pursued economic or political objectives. According to Li [12], the cultural norms of target countries play a key role in explaining the effectiveness of sanctions. The implication of the study is the introduction of effective and reliable economic sanctions as an instrument of foreign policy must be conditioned by considering cultural responsibility and sensitivity of objectives. The USA imposes a number of economic sanctions on China (export controls, bans on certain imported goods, etc.). Yang et al. [13] found that although the U.S. sanctions did not have a significant impact on the trade between the two countries and the 
overall Chinese economic growth, they do affect negatively the behaviour of consumers and producers both in the USA and China.

In 2019, China stated it would impose sanctions on U.S. enterprises involved in the contract on selling missiles, tanks, and the related equipment of $\$ 2.2$ billion to Taiwan. According to the People's Republic of China, this harmed the national security and sovereignty of China. The spokesman of the Chinese Ministry of Foreign Affairs said that the U.S. sale of arms is a very serio U.S. violation of the basic standards governing international relations and international law [14]. According to Pandey [15], the U.S. President Donald Trump blocked Chinese Huawei. Huawei's major U.S. suppliers reportedly announced an immediate supply to the Chinese company. Google then struck by announcing that Huawei would block certain applications and services for Android on their devices. Including Huawei in the blacklist of U.S. technology enterprises resulted in Huawei's ban on producing smartphones and tablets for sale outside China and selling notebooks anywhere.

This article should also mention machine learning. Machine learning is basically a branch of artificial intelligence. Machine learning deals with algorithms and methods that can enable a computer system to learn - this refers to the change in the internal state of the system that will make the ability to adapt to the changes of the environment more effective [16]. Vrbka and Rowland [17] adds that artificial neural networks are computational models inspired by biological neural networks, which are used for a number of different areas and points out that an artificial neural network has the potential for accurate prediction based on nonlinear data. According to Zhong and Enke [18], the methods of big data analysis associated with the algorithms of machine learning play an increasingly significant role in various areas of application, including the investment in the stock market. Deep neural networks use various algorithms for deep learning based on the combination of the network structure, activation function, and the parameters of a model, where their performance depends on the format of the data representation [17]. Thanks to other hidden layers and complex algorithms of learning, deep neural networks are recognized as an important and advanced technology in the area of computational and artificial intelligence [19]. Vrbka and Rowland [17] claim that the advantage of deep learning is the analysis and the ability to learn a huge amount of data without a teacher, which makes it a valuable instrument for the big data analysis, where the data are mostly unmarked and unclassified. Moreover, when the heterogeneity of the sample is regulated, the new hybrid method is more likely to achieve the correct balance in terms of both noise and trend, which results in excellent prediction efficiency [20].

\section{Data and methods}

The objective of the contribution is to use machine learning for predicting the future values of the mutual trade between the Czech Republic (hereinafter referred to as "the CR) and the People's Republic of China (hereinafter referred to as "the PRC) for one calendar year (i.e. 12 months).

At present, the global trend is influenced not only by mutual sanctions between the PRC and the United States of America (USA) and between the Russian Federation and the USA. Moreover, it is necessary to consider the difficulties and problems caused by the measures adopted in relation to COVID-19. However, the world trade balance or the CR-PRC trade balance is affected by this extraordinary situation. Therefore, this should be taken into account when formulating the research question: Is machine learning able to take into consideration the extraordinary situation in the world caused by the sanctions of trade powers and measures adopted against COVID-19 when predicting the mutual trade of the CR and the PRC?

The data for the analysis are available on the websites of the Czech Statistical Office. For the purposes of the analysis, the information on the CR export and import from/to the PRC. 
Moreover, the trade balance of both countries will be calculated from the perspective of the CR. The data will be taken for the interval starting from January 2005 to April 2020. In total, the data for 184 months of the monitored time series will be included in the calculation. The trend shows a significant increase in the CR import from the PRC. This determines the development of mutual trade balance, which is remarkably negative from the perspective of the $\mathrm{CR}$ and is still growing over time. The CR import from the PRC exceeds the CR export to the PRC several times. It is thus interesting to find out how mutual trade will be affected by the decline of the Chinese GDP in the first quarter of the year 2020, which is nearly $25 \%$ compared to the previous quarter.

For the data processing, TIBCO's Statistica software, version 13, will be used. There will be performed the regression of the export and import time series using neural structures. The trade balance will be determined by the difference of smoothed time series (their prediction for one year). The solution process will be in the form of an experiment. For both time series, the time lag of one, six, and twelve months will be considered. This means that any other value will be predicted on the basis of one, six, or twelve (preceding) months. In the case of one month, the result will be sensitive to a possible fluctuation. In case there are more periods necessary to be considered for the calculation, the time series will be more or less able to cope with such a fluctuation in time series smoothing or predicting. Multilayer perceptron networks and radial basis function networks will be generated. There will be monitored the year-on-year development of the time series as well as the development between the individual months, as seasonal fluctuations within one year can be assumed. The variables included in the calculation will be year, month, and import as independent variables, and export as an output, dependent variable.

The calculation in all three cases must be analogous. The time series will be divided into three data sets - training, testing, and validation. The first data set will contain $70 \%$ of the input data and be used for the generation of neural structures. The remaining two data sets will contain $15 \%$ of the input information each. Both sets will be used for the verification of the generated neural structure or model reliability. The descriptive characteristics of the time series describing the CR export to the PRC and import from PRC are given in Table 1.

Table 1. Characteristics of data sets - time series of CR export to PRC and import from PRC

\begin{tabular}{|c|c|c|c|c|}
\hline \multirow{2}{*}{ Samples } & \multirow{2}{*}{ Year } & \multirow{2}{*}{ Month } & \multicolumn{2}{|c|}{ Export/Import (mil. CZK) } \\
\hline & & & Export & Import \\
\hline Minimum (Train) & 2005.000 & 1.00000 & 181.000 & 6142.00 \\
\hline Maximum (Train) & 2020.000 & 12.00000 & 4218.000 & 41720.00 \\
\hline Mean (Train) & 2011.838 & 6.47692 & 2105.900 & 21656.33 \\
\hline Standard deviation (Train) & 4.425 & 3.40136 & 1070.642 & 7340.31 \\
\hline Minimum (Test) & 2005.000 & 1.00000 & 486.000 & 9253.00 \\
\hline Maximum (Test) & 2019.000 & 12.00000 & 3873.000 & 30363.00 \\
\hline Mean (Test) & 2012.074 & 5.03704 & 2146.111 & 21380.44 \\
\hline Standard deviation (Test) & 4.590 & 3.11919 & 1153.651 & 6221.42 \\
\hline Minimum (Validation) & 2005.000 & 1.00000 & 629.000 & 7400.00 \\
\hline Maximum (Validation) & 2020.000 & 12.00000 & 4218.000 & 35348.00 \\
\hline Mean (Validation) & 2013.889 & 7.48148 & 2618.667 & 25326.19 \\
\hline Standard deviation (Validation) & 8.406 & 3.92849 & 2026.807 & 15061.26 \\
\hline Minimum (Overall) & 2005.000 & 1.00000 & 181.000 & 6142.00 \\
\hline Maximum (Overall) & 2020.000 & 12.00000 & 4218.000 & 41720.00 \\
\hline Mean (Overall) & 2012.174 & 6.41304 & 2187.043 & 22154.36 \\
\hline Standard deviation (Overall) & 4.442 & 3.47718 & 1079.389 & 7098.69 \\
\hline
\end{tabular}

There will be generated 100,000 neural networks, out of which 5 with the best characteristics will be retained. The hidden layer contains 2-20 neurons. In the case of the 
radial basis function, the hidden layer contains at least 21 neurons (31 at most). For multilayer perceptron networks, the following activation function in the hidden and output layers are considered: Linear, Logistic, Atanh, Exponential, Sine.

Other settings remain default (according to the ANN - Automated Neural Networks). If necessary, the results will be modified by means of ONN (Own Neural Networks). However, it is a manual intervention in the weights of neural networks; possible improvement of the neural networks' performance is thus rather coincidental. Such corrected resulting neural networks will be used for predicting import and export, and calculation of the CR-PRC trade balance until the end of the monitored period, that is, for twelve months.

\section{Results}

\subsection{Export}

The resulting set of neural networks will be based on the performance of the individual neural structures and errors that they show in the individual data sets. The overview of generated and retained neural networks is shown in Table 2.

Table 2. Retained neural networks - CR export to PRC

\begin{tabular}{|c|c|c|c|c|c|c|c|c|c|c|c|}
\hline Index & Net. name & $\begin{array}{c}\text { Training } \\
\text { perf. }\end{array}$ & $\begin{array}{l}\text { Test } \\
\text { perf. }\end{array}$ & $\begin{array}{c}\begin{array}{c}\text { Validation } \\
\text { perf. }\end{array} \\
\end{array}$ & $\begin{array}{c}\begin{array}{c}\text { Training } \\
\text { error }\end{array} \\
\end{array}$ & $\begin{array}{l}\text { Test } \\
\text { error }\end{array}$ & \begin{tabular}{|c|}
$\begin{array}{c}\text { Validation } \\
\text { error }\end{array}$ \\
\end{tabular} & \begin{tabular}{|c|} 
Training \\
algorithm
\end{tabular} & \begin{tabular}{|c|}
$\begin{array}{c}\text { Error } \\
\text { function }\end{array}$ \\
\end{tabular} & $\begin{array}{c}\text { Hidden } \\
\text { activation }\end{array}$ & \begin{tabular}{|c|}
$\begin{array}{c}\text { Output } \\
\text { activation }\end{array}$ \\
\end{tabular} \\
\hline 1 & $\begin{array}{c}\mathrm{RBF} \\
2-21-1\end{array}$ & 0.974929 & 0.972928 & 0.966684 & 27365.36 & 35751.03 & 30271.92 & RBFT & SOS & Gaussian & Identity \\
\hline 2 & $\begin{array}{c}\mathrm{RBF} \\
2-30-1\end{array}$ & 0.971980 & 0.970605 & 0.967931 & 30529.29 & 38199.89 & 31451.29 & RBFT & SOS & Gaussian & Identity \\
\hline 3 & $\begin{array}{c}\mathrm{RBF} \\
2-28-1\end{array}$ & 979677 & 0.976819 & 0.968913 & 22197.98 & 33671.73 & 29080.36 & RBFT & SOS & Gaussian & Identity \\
\hline 4 & $\begin{array}{c}\mathrm{RBF} \\
2-27-1\end{array}$ & 976272 & 0.967320 & 0.967033 & 25890.59 & 42486.56 & 30109.73 & RBFT & SOS & Gaussian & Identity \\
\hline 5 & $\begin{array}{c}\mathrm{RBF} \\
2-22-1\end{array}$ & 0.972228 & 0.964288 & 0.969674 & 30260.60 & 45031.57 & 27455.82 & RBFT & SOS & Gaussian & Identity \\
\hline 1 & $\begin{array}{c}\text { MLP } \\
12-3-1\end{array}$ & 0.975355 & 0.983508 & 0.947916 & 22459.13 & 23111.17 & 36990.22 & BFGS 144 & SOS & Logistic & Identity \\
\hline 2 & $\begin{array}{c}\text { MLP } \\
12-3-1\end{array}$ & 0.975624 & 0.976220 & 0.949407 & 22213.78 & 30244.14 & 36982.26 & BFGS 138 & SOS & Logistic & Identity \\
\hline 3 & $\begin{array}{c}\text { MLP } \\
12-7-1 \\
\end{array}$ & 978157 & 0.982231 & 0.949054 & 19677.52 & 23072.61 & 41297.78 & BFGS 123 & SOS & Tanh & Sine \\
\hline 4 & $\begin{array}{c}\text { MLP } \\
12-9-1\end{array}$ & 0.976150 & 0.979882 & 0.947117 & 21676.53 & 27123.04 & 38198.81 & BFGS 58 & SOS & Tanh & Identity \\
\hline 5 & $\begin{array}{c}\text { MLP } \\
12-8-1\end{array}$ & 0.976901 & 0.979368 & 0.947595 & 20928.46 & 26475.53 & 39797.08 & BFGS 76 & SOS & Tanh & Identity \\
\hline 1 & $\begin{array}{c}\text { MLP } \\
24-4-1 \\
\end{array}$ & 0.962044 & 0.964959 & 0.950549 & 28190.06 & 32318.56 & 34610.19 & BFGS 42 & SOS & Tanh & Sine \\
\hline 2 & $\begin{array}{c}\text { MLP } \\
24-4-1\end{array}$ & 0.949454 & 0.954320 & 0.948780 & 40611.52 & 45490.47 & 39200.03 & BFGS 10 & SOS & Sine & Sine \\
\hline 3 & $\begin{array}{c}\text { MLP } \\
24-4-1 \\
\end{array}$ & 0.966674 & 0.966746 & 0.950867 & 23902.90 & 32621.72 & 34306.20 & BFGS 15 & SOS & Tanh & Logistic \\
\hline 4 & $\begin{array}{c}\text { MLP } \\
24-3-1 \\
\end{array}$ & 0.961232 & 0.965008 & 0.948888 & 29470.28 & 32218.64 & 36650.74 & BFGS 15 & SOS & Exponential & Sine \\
\hline 5 & $\begin{array}{c}\text { MLP } \\
24-4-1\end{array}$ & 0.960240 & 0.965737 & 0.949825 & 31393.64 & 30533.96 & 38134.81 & BFGS 9 & SOS & Sine & Sine \\
\hline
\end{tabular}

The method of least squares will be used. Generation of networks will be finished when there is no improvement, that is until the sum of squares is reduced. There will be retained the neural networks whose residual sum of squares to the actual development of the CR and PRC trade balance is as low as possible (zero in the ideal case).

All retained neural networks show excellent performance and relatively small errors. The first five neural networks in the table consider the time lag of 1 month, in the case of the other five neural networks it is a 6-month lag, and a 12-month lag in the case of the remaining five 
networks. The time lag is evident from the number of the input neurons, where the number of neurons is divided by the number of variables included in the calculation, thus giving the length of the smoothed time series lag. The error function is the sum of least squares. The objective is to find a neural network that shows high performance that would be identical in all three data sets in the ideal case, and a network with as small error as possible. It is not possible to identify at first sight the network with the best parameters; however, it can be stated that it is one of the networks working with a 1-month lag. Table 3 shows the characteristics of the smoothed time series with a 1-month lag.

Table 3. Characteristics of smoothed time series created by means of neural networks with 1-month lag - CR export to PRC

\begin{tabular}{|l|r|r|r|r|r|}
\hline \multicolumn{1}{|c|}{ Statistics } & \multicolumn{1}{|c|}{$\mathbf{\text { RBF }}$} & $\mathbf{2 . R B F}$ & $\mathbf{3 . R B F}$ & $\mathbf{4 . R B F}$ & $\mathbf{5 . R B F}$ \\
& $\mathbf{2 - 2 1 - 1}$ & $\mathbf{2 - 3 0 - 1}$ & $\mathbf{2 - 2 8 - 1}$ & $\mathbf{2 - 2 7 - 1}$ & $\mathbf{2 - 2 2 - 1}$ \\
\hline Minimum prediction (Train) & 471.554 & 393.303 & 439.816 & 608.979 & 468.016 \\
\hline Maximum prediction (Train) & 3928.951 & 3968.292 & 3936.168 & 3902.964 & 3810.358 \\
\hline Minimum prediction (Test) & 640.795 & 441.591 & 396.973 & 583.368 & 598.287 \\
\hline Maximum prediction (Test) & 3896.421 & 3569.898 & 3576.540 & 3478.992 & 3538.990 \\
\hline Minimum prediction (Validation) & 563.716 & 895.221 & 599.172 & 629.254 & 545.989 \\
\hline Maximum prediction (Validation) & 3803.923 & 3794.420 & 3816.524 & 3642.345 & 3657.611 \\
\hline Minimum residual (Train) & -574.867 & -682.536 & -561.874 & -722.033 & -636.746 \\
\hline Maximum residual (Train) & 748.204 & 681.198 & 891.714 & 675.515 & 950.678 \\
\hline Minimum residual (Test) & -406.270 & -443.898 & -254.581 & -426.290 & -467.466 \\
\hline Maximum residual (Test) & 592.237 & 442.357 & 576.890 & 633.204 & 534.917 \\
\hline Minimum residual (Validation) & -594.697 & -600.840 & -485.889 & -412.136 & -504.611 \\
\hline Maximum residual (Validation) & 544.747 & 524.210 & 401.476 & 575.655 & 595.923 \\
\hline Minimum standard residual (Train) & -3.475 & -3.906 & -3.771 & -4.487 & -3.660 \\
\hline Maximum standard residual (Train) & 4.523 & 3.899 & 5.985 & 4.198 & 5.465 \\
\hline Minimum standard residual (Test) & -2.149 & -2.271 & -1.387 & -2.068 & -2.203 \\
\hline Maximum standard residual (Test) & 3.132 & 2.263 & 3.144 & 3.072 & 2.521 \\
\hline Minimum standard residual (Validation) & -3.418 & -3.388 & -2.849 & -2.375 & -3.045 \\
\hline Maximum standard residual (Validation) & 3.131 & 2.956 & 2.354 & 3.317 & 3.596 \\
\hline
\end{tabular}

The results of the individual networks differ mainly in terms of the minimum values. To choose the most suitable network, it is necessary to compare the graphs of the smoothed time series and predictions of time series. Based on the analysis and with regard to the actual development of the CR export to the PRC, as well as in light of events of recent months and years (sanctions, COVID-19), the development predicted by the neural network 3. RBF 228-1 appears to be the most probable.

\subsection{Import}

The neural networks retained from individual experiments and based on the change in the time series lag are shown in Table 4. 
Table 4. Retained neural networks - CR import from PRC

\begin{tabular}{|c|c|c|c|c|c|c|c|c|c|c|c|}
\hline Index & $\begin{array}{c}\text { Net. } \\
\text { name }\end{array}$ & \begin{tabular}{|c|} 
Training \\
perf.
\end{tabular} & $\begin{array}{l}\text { Test } \\
\text { perf. }\end{array}$ & $\begin{array}{c}\text { Validation } \\
\text { perf. }\end{array}$ & $\begin{array}{c}\text { Training } \\
\text { error }\end{array}$ & $\begin{array}{l}\text { Test } \\
\text { error }\end{array}$ & $\begin{array}{c}\text { Validation } \\
\text { error }\end{array}$ & \begin{tabular}{|c|} 
Training \\
algorithm
\end{tabular} & \begin{tabular}{|c|}
$\begin{array}{c}\text { Error } \\
\text { function }\end{array}$ \\
\end{tabular} & \begin{tabular}{|c|} 
Hidden \\
activation
\end{tabular} & $\begin{array}{c}\text { Output } \\
\text { activation }\end{array}$ \\
\hline 1 & $\begin{array}{l}\text { MLP } \\
2-8-1\end{array}$ & .956833 & 0.907289 & 0.937412 & 2177970 & 3394536 & 2372015 & BFGS 100 & SOS & Tanh & Logistic \\
\hline 2 & $\begin{array}{l}\text { MLP } \\
2-7-1\end{array}$ & 0.965249 & 0.919301 & 0.937357 & 1757968 & 2948873 & 2468694 & BFGS 137 & SOS & Tanh & Identity \\
\hline 3 & \begin{tabular}{|l|} 
MLP \\
$2-7-1$
\end{tabular} & 0.950447 & 0.917063 & 0.937083 & 2491522 & 3247880 & 2254966 & BFGS 86 & SOS & Logistic & Logistic \\
\hline 4 & $\begin{array}{l}\text { MLP } \\
2-7-1\end{array}$ & 0.949795 & 0.921219 & 0.939025 & 2541460 & 2995639 & 2106491 & BFGS 76 & SOS & Logistic & Logistic \\
\hline 5 & $\begin{array}{l}\text { MLP } \\
2-9-1\end{array}$ & 0.953262 & 0.925814 & 0.936160 & 2350278 & 2875775 & 2363162 & BFGS 76 & SOS & Tanh & Identity \\
\hline 1 & \begin{tabular}{|l|} 
MLP \\
$12-5-1$ \\
\end{tabular} & 949207 & 0.938217 & 0.900289 & 2117449 & 2521392 & 2279652 & BFGS 124 & SOS & Logistic & Exponential \\
\hline 2 & \begin{tabular}{|l}
$\mathrm{RBF}$ \\
$12-22-1$ \\
\end{tabular} & 0.885421 & 0.838899 & 0.900397 & 4797659 & 5616602 & 2712598 & RBFT & SOS & Gaussian & Identity \\
\hline 3 & \begin{tabular}{|l|} 
MLP \\
$12-7-1$
\end{tabular} & 0.950131 & 0.927301 & 0.895146 & 2077971 & 2877564 & 2484067 & BFGS 62 & SOS & Logistic & Exponential \\
\hline 4 & \begin{tabular}{|l} 
MLP \\
$12-6-1$
\end{tabular} & 0.946798 & 0.943225 & 0.895085 & 2221901 & 2524514 & 2229639 & BFGS 68 & SOS & Tanh & Logistic \\
\hline 5 & \begin{tabular}{|l} 
MLP \\
$12-4-1$
\end{tabular} & 0.955523 & 0.917210 & 0.899437 & 1841871 & 3118734 & 2540275 & BFGS 136 & SOS & Logistic & Identity \\
\hline 1 & \begin{tabular}{|l|} 
MLP \\
$24-4-1$
\end{tabular} & 0.883647 & 0.866382 & 0.903628 & 4233564 & 3868181 & 1971705 & BFGS 30 & SOS & Sine & Tanh \\
\hline 2 & \begin{tabular}{|l} 
MLP \\
$24-4-1$
\end{tabular} & 0.925341 & 0.895536 & 0.904582 & 2637684 & 2922535 & 2049864 & BFGS 20 & SOS & Sine & Logistic \\
\hline 3 & \begin{tabular}{|l|} 
MLP \\
$24-8-1$
\end{tabular} & 0.926330 & 0.892544 & 0.906638 & 2616843 & 2627411 & 1891023 & BFGS 10 & SOS & Exponential & Logistic \\
\hline 4 & \begin{tabular}{|l} 
MLP \\
$24-4-1$
\end{tabular} & 0.920838 & 0.892505 & 0.908703 & 3162888 & 2653749 & 2070969 & BFGS 15 & SOS & Sine & Tanh \\
\hline 5 & \begin{tabular}{|l} 
MLP \\
$24-6-1$
\end{tabular} & 0.906090 & 0.880075 & 0.905068 & 3450094 & 3057076 & 2254743 & BFGS 18 & SOS & Sine & Logistic \\
\hline
\end{tabular}

All retained neural networks show excellent results. Except for two neural networks (2. RBF 12-22-1 and 1. MLP 24-4-1), it can be stated that the performance of all neural networks is excellent. The error function used for all neural networks was the sum of least squares.

Table 5. Characteristics of smoothed time series created using neural networks with 1-month lag CR import from PRC

\begin{tabular}{|l|r|r|r|r|r|}
\hline \multicolumn{1}{|c|}{ Statistics } & \multicolumn{1}{c|}{$\begin{array}{c}\text { MLP } \\
\text { 2-8-1 }\end{array}$} & $\begin{array}{c}\text { 2.MLP } \\
\mathbf{2 - 7 - 1}\end{array}$ & $\begin{array}{c}\text { 3.MLP } \\
\mathbf{2 - 7 - 1}\end{array}$ & $\begin{array}{c}\text { 4.MLP } \\
\mathbf{2 - 7 - 1}\end{array}$ & \multicolumn{1}{c|}{$\begin{array}{c}\text { 5.MLP } \\
\mathbf{2 - 9 - 1}\end{array}$} \\
\hline Minimum prediction (Train) & \multicolumn{1}{c|}{8624.29} & 7768.02 & 8965.20 & 8924.79 & 6276.00 \\
\hline Maximum prediction (Train) & 38118.49 & 40243.27 & 37677.18 & 36925.54 & 39452.24 \\
\hline Minimum prediction (Test) & 9102.73 & 9702.41 & 9398.08 & 9493.91 & 9074.27 \\
\hline Maximum prediction (Test) & 30487.42 & 29925.20 & 30310.15 & 29596.94 & 29917.96 \\
\hline Minimum prediction (Validation) & 8671.65 & 8086.48 & 9003.66 & 9017.47 & 6508.80 \\
\hline Maximum prediction (Validation) & 36004.46 & 36115.78 & 36165.25 & 35295.14 & 35936.56 \\
\hline Minimum residual (Train) & -4837.24 & -4656.02 & -4273.04 & -4363.90 & -4307.64 \\
\hline Maximum residual (Train) & 5146.59 & 4242.11 & 6402.91 & 7245.67 & 6056.89 \\
\hline Minimum residual (Test) & -3381.67 & -3888.58 & -3058.11 & -3756.29 & -3012.74 \\
\hline Maximum residual (Test) & 7723.36 & 7689.65 & 7696.69 & 6995.24 & 7069.93 \\
\hline Minimum residual (Validation) & -3847.90 & -4175.88 & -4348.60 & -3532.51 & -3664.30 \\
\hline Maximum residual (Validation) & 4074.98 & 3908.95 & 4416.33 & 4204.65 & 5082.76 \\
\hline Minimum standard residual (Train) & -3.28 & -3.51 & -2.71 & -2.74 & -2.81 \\
\hline Maximum standard residual (Train) & 3.49 & 3.20 & 4.06 & 4.55 & 3.95 \\
\hline Minimum standard residual (Test) & -1.84 & -2.26 & -1.70 & -2.17 & -1.78 \\
\hline Maximum standard residual (Test) & 4.19 & 4.48 & 4.27 & 4.04 & 4.17 \\
\hline Minimum standard residual (Validation) & -2.50 & -2.66 & -2.90 & -2.43 & -2.38 \\
\hline Maximum standard residual (Validation) & 2.65 & 2.49 & 2.94 & 2.90 & 3.31 \\
\hline
\end{tabular}


From the perspective of the neural networks' performance and error, it can be stated that the best results are shown by the networks working with the time lag of 1 calendar month. In all data sub-sets, the correlation coefficient of all retained networks working with the 1month lag achieves the value of 0.91 or higher. Table 5 shows the characteristics of the smoothed time series with a 1-month lag.

The results of individual time series differ in terms of the values of the smoothed time series as well as in the residuals' values. To choose the most suitable network, the graphs of smoothed time series and predictions are compared. It seems that the neural network 1. MLP 2-8-1 smoothes the time series best. This result is also indicated by slightly better characteristics of the performance, error, and resulting residuals.

\section{Discussion}

The results clearly show the development of the monitored time series - export, import, and the trade balance (for more details, see Figure 1).

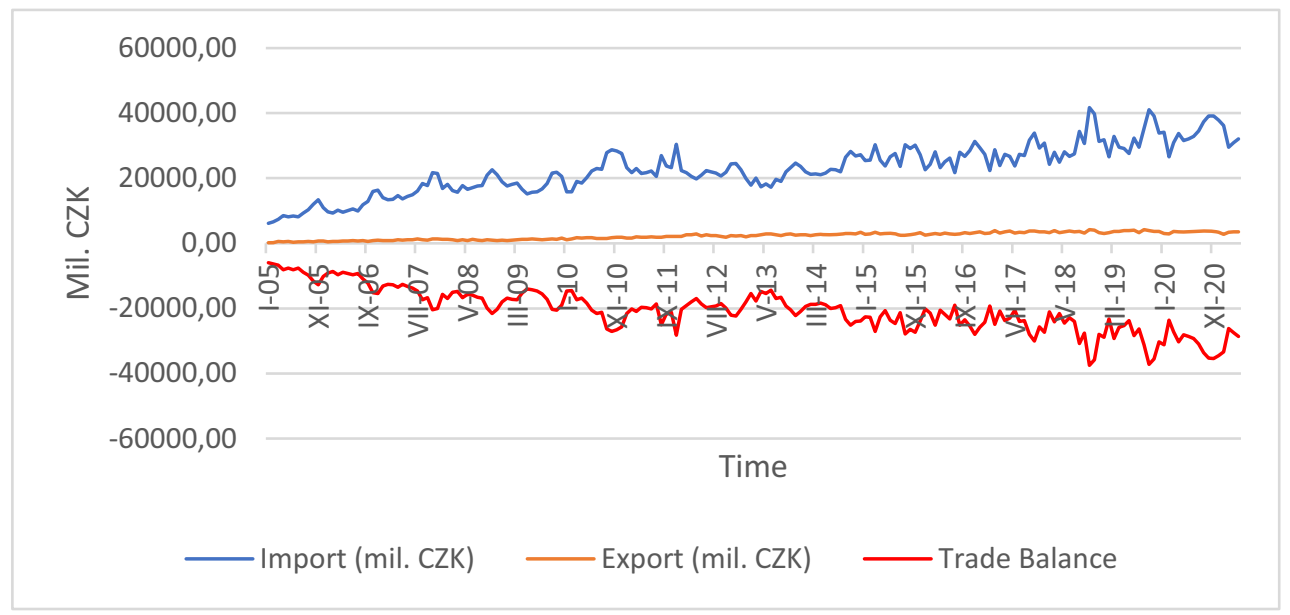

Fig. 1. Development of CR-PRC trade balance including the prediction until 30 April 2021

The figure indicates a slight decrease in the CR import from the PRC. This corresponds with the further development of both countries' trade balance. The CR export to the PRC does not play a significant role in mutual trade relations. However, the question is whether machine learning prediction was able to capture the correct signals from both countries, which would indicate the future development, as a different development of import would be expected. Here, it should be noted the aforementioned fact that the performance of Chinese economics measured by means of GDP fell nearly by $25 \%$ in the first quarter of 2020 . In this context, the prediction of the network 2. RBF 12-22-1 appears to be the most accurate one (Figure 2). 


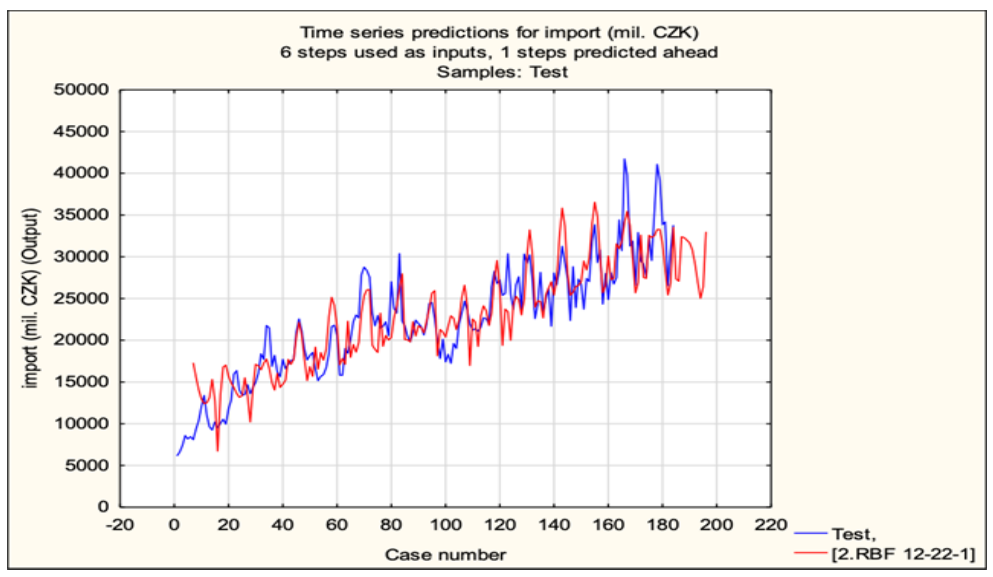

Fig. 2. Smoothed time series and prediction of CR import from PRC until 30 April 2021

The available data on the development of the Chinese and global economy could indicate the decrease in the CR import from the PRC predicted by 2. RBF 12-22-1. However, the neural structure smoothes the time series incorrectly (even at its beginning and also at its final stage).

Nevertheless, the truth is that although the decrease in the performance of Chinese economics was noted in the first quarter of 2020, it did not affect the volume of the CR import from the PRC. This could be explained by the fact that Chinese enterprises lost other markets in the world. The reason could be in the limitation of the transport of goods caused by the restrictive measures adopted against COVID-19 or the fear of persons and enterprises to import goods from China, as the PRC has been considered to be a country where COVID-19 originated. In light of these negative events, the PRC tried to preserve its traditional markets as much as possible. The CR has always been one of the traditional markets for China; therefore, despite the decrease in the Chinese production, there has been no decrease in the $\mathrm{CR}$ import from the PRC, and, as the predictions of the monitored time series indicate, this will probably not happen. Here is thus the response to the formulated research questions. The extraordinary situation caused by COVID-19 and the sanctions in international trade were not, with certain exceptions, considered by the neural networks. Despite this, the result may not be erroneous; quite the opposite, the predicted development may turn out to be correct.

\section{Conclusion}

The objective of the contribution was to use machine learning for predicting the values of the mutual trade between the Czech Republic (the CR) and the People's Republic of China (the $\mathrm{PRC}$ ) for one calendar year (12 months).

A total of 300,000 artificial neural networks with a time series lag of one, six, and twelve months were generated to smooth the time series of the CR export to the PRC and 300,000 artificial neural networks with a time series lag of one, six, and twelve months were generated to smooth the time series of the CR import from the PRC. For each time lag and each time series, 5 artificial neural networks with the best characteristics of the smoothed time series were retained. The resulting neural networks and smothed time series were subsequently analysed. For both export and import, the most suitable neural networks were chosen; more specifically, the network 3. RBF 2-28-1 for export and 1. MLP 2-8-1 for import. The networks were then used to predict the development of the time series for the period until 30 April 2021. The difference of the predictions indicated the mutual CR and PRC trade balance. This is expected to be negative from the perspective of the CR. The Czech government is 
thus recommended to tackle the unfavourable situation. The difference of the export and import between the CR and the PRC should be minimal.

The whole conclusion is based on the assumption that COVID-19 or the sanctions imposed in the international trade will not significantly affect the development of the mutual trade between the CR and the PRC.

\section{References}

1. Drábek, J., Lipková, L., Gress, M. (2015). Development of the balance of payments in The Czech Republic since 1993 with the emphasis on current account. Economic Annals$X X I, 7-8(2)$, 4-7.

2. Li, N., Sun, L. P., Luo, X., Kang, R., Jia, M.D. (2019). Foreign trade structure, opening degree and economic growth in Western China. Economies, 7(2).

3. Fürst, R., Pleschová, G. (2010). Czech and Slovak relations with China: Contenders for China's favour. Europe-Asia Studies, 62(8), 1363-1381.

4. Hnát, P., Tlapa, M. (2014). China-V4 investment regime - a Czech perspective. In P. Mraz \& M. Tlapa (Eds.), CurrentTrends and Perspectives in Development of China - V4 Trade and Investment (pp. 82-95). Bratislava: Vydavatelstvo Ekonom.

5. Lemoine, F., Unal, D. (2017). China's foreign trade: A "new normal”. China \& World Economy, 25(2), 1-21.

6. Gourdon, J., Monjon, S., Poncet, S. (2016). Trade policy and industrial policy in China: What motivates public authorities to apply restrictions on exports? China Economic Review, 40, 105-120.

7. Stehel, V., Suleř, P. (2016). Foreign trade between China and the Czech Republic. Littera Scripta, 9(3), 84-95.

8. Higgins, P., Tha, T., Zhong, W. (2016). Forecasting China's economic growth and inflation. China Economic Review, 41, 46-61.

9. Liu, X., Li, X., Li, H. (2016). R\&D subsidies and business R\&D: Evidence from hightech manufacturing firms in Jiangsu. China Economic Review, 41, 1-22.

10. Czech Statistical Office (2018, November 20). Když se řekne zahranični obchod [When you say foreign trade]. Retrieved from: https://www.czso.cz

11. MZV (2019, October 16). Č́na: Obchodní a ekonomická spolupráce s ČR [China: Trade and economic cooperation with the Czech Republic]. BusinessInfo: Official portal for business and export. Retrieved from: https:/www.businessinfo.cz/cs/clanky/cinaobchodni-a-ekonomicka-spoluprace-s-cr-19054.html

12. Li, Y. (2014). U.S. Economic sanctions against China: A cultural explanation of sanction effectiveness. Asian Perspective, 38(2), 311-335.

13. Yang, J., Askari, H., Forrer, J., Teegen, H. (2004). U.S. Economic sanctions against China: Who gets hurt? World Economy, 27(7), 1047-1081.

14. The Guardian (2019, October 8). China vows to impose sanctions on U.S. firms supplying Taiwan military. from: https://www.theguardian.com/world/2019/jul/12/china-taiwan-sanctions-us-firmsmilitary-sales

15. Pandey, A. (2019, October 8). U.S. - China trade war: Huawei's loss is Samsung's gain. DW: Made for minds. Retrieved from: https:/www.dw.com/en/us-china-trade-warhuaweis-loss-is-samsungs-gain/a-48814477 
16. Vochozka, M., Rowland, Z., Šuleř, P., Maroušek, J. (2020). The influence of the international price of oil on the value of the EUR/USD exchange rate. Journal of Competitiveness, 12(2), 167-190.

17. Vrbka, J., Rowland, Z. (2017). Stock price development forecasting using neural networks. In J. Váchal, M. Vochozka \& J. Horák (Eds.), SHS Web of Conferences Innovative Economic Symposium 2017: Strategic Partnership in International Trade. Les Ulis, France: EDP Sciences.

18. Zhong, X., Enke, D. (2019). Predicting the daily return direction of the stock market using hybrid machine learning algorithms. Financial Innovation, 5(1).

19. Vrbka, J. (2020). The use of neural networks to determine value based drivers for SMEs operating in the rural areas of the Czech Republic. Oeconomia Copernicana, 11(2), 325 346.

20. Kliestik, T., Misankova, M., Valaskova, K., Svabova, L. (2018). Bankruptcy prevention: new effort to reflect on legal and social changes. Science and Engineering Ethics, 24(2), 791-803. 